\title{
A comparative study of the effect of multiple immersions on Aedini (Diptera: Culicidae) mosquito eggs with emphasis on sylvan vectors of yellow fever virus
}

\author{
Jeronimo Alencar ${ }^{1 /+}$, Raquel Miranda Gleiser ${ }^{2,3}$, Fernanda Morone ${ }^{1}$, Cecília Ferreira de Mello $^{1}$, \\ Júlia dos Santos Silva', Nicolau Maués Serra-Freire ${ }^{4}$, Anthony Érico Guimarães ${ }^{1}$ \\ ${ }^{1}$ Laboratório de Diptera ${ }^{4}$ Laboratório de Referência Nacional para Rickettsioses, Instituto Oswaldo Cruz-Fiocruz, \\ Rio de Janeiro, RJ, Brasil ${ }^{2}$ Centro de Relevamiento y Evaluación de Recursos Agrícolas y Naturales, \\ Consejo Nacional de Investigaciones Científicas y Técnicas, Córdoba, Argentina ${ }^{3}$ Cátedra de Ecología, \\ Facultad de Ciencias Exactas Fisicas y Naturales, Universidad Nacional de Córdoba, Córdoba, Argentina
}

The effect of multiple immersions on Haemagogus janthinomys, Haemagogus leucocelaenus, Aedes albopictus and Ochlerotatus terrens eggs was studied. Eggs were collected in April, June, October and December of 2011 in Minas Gerais, Brazil. Most of the Aedes and Ochlerotatus eggs hatched upon the first immersion, while Haemagogus eggs showed a varied instalment hatching response. The number of immersions required for hatching increased for eggs collected closer to the dry winter season.

Key words: Culicidae - Haemagogus - egg-hatching - immersion - dormancy

Mosquitoes of the genus Haemagogus have been studied in North and South America (Marcondes \& Alencar 2010) due to their medical relevance as vectors of the yellow fever virus, Mayaro and other arboviruses. Species of this genus show a preference for ovipositing in cavities and tree holes, but can be found colonising bamboo internodes and fruit shells as well (Arnell 1973). Aedes albopictus Skuse and Ochlerotatus terrens (Walker) (= Aedes terrens) (Reinert et al. 2008) also utilise a wide variety of natural microhabitats, such as tree holes, bamboo internodes and artificial containers and may be found in the same environments as Haemagogus. Ae. albopictus is a culicid of Asian origin that has dispersed widely to other continents since the 1980s and acts as a natural dengue vector in rural, suburban and urban areas in Asia where virus transmission occurs (Consoli \& Lourenço-de-Oliveira 1994).

Dormancy of the egg stage (and drought resistance) is considered to be a reproductive strategy for the longterm survival of multivoltine mosquitoes that develop in temporary habitats, such as tree holes and other natural water containers that are subject to water fluctuations (Vinogradova 2007). Egg diapause involves a long stable arrest of hatching, even when environmental conditions are favourable for hatching. In contrast, aseasonal quiescence is induced by unfavourable environmental

doi: 10.1590/0074-0276130168

Financial support: Furnas-Centrais Elétricas SA (P-1031-00-PJ-/08), FAPERJ (112.076/2012)

RMG is a career member of CONICET.

+ Corresponding author: jalencar@ioc.fiocruz.br

Received 25 March 2013

Accepted 9 September 2013 conditions and ceases shortly after exposure to adequate hatching stimuli, such as flooding (Mullen \& Durden 2009). Nevertheless, some quiescent eggs may require more than one flooding event to hatch, which is known as instalment hatching (Gillett 1955).

Haemagogus, Aedes and Ochlerotatus lay their drought-resistant eggs on damp substrates, where they can remain quiescent after embryogenesis for varying lengths of time (Gillett 1955, Campos \& Sy 2006, Mullen $\&$ Durden 2009). Knowledge about the onset and termination of dormancy, the period of reproductive activity and number of generations provides a predictive capability, which is important for developing mosquito control strategies (Vinogradova 2007). The aim of this study was to explore the response to multiple immersions in eggs of Haemagogus janthinomys Dyar, Haemagogus leucocelaenus (Dyar \& Shannon), Ae. albopictus and Oc. terrens that were collected in different seasons.

The eggs were collected with ovitraps following the methodology described by Alencar et al. (2004). The traps consisted of $1 \mathrm{~L}$ matte black plastic containers filled with water and litterfall (to simulate natural conditions) and four wooden paddles $(14 \mathrm{~cm} \times 2.5 \mathrm{~cm}) \mathrm{se}-$ cured with paper clips. Egg collections were performed in April, June, October and December of 2011 in the area of Simplício Hydroelectric Complex (AHES), state of Minas Gerais, Brazil. The sampling points were located at $22^{\circ} 05^{\prime} 37^{\prime \prime} \mathrm{S} 43^{\circ} 05^{\prime} 03^{\prime \prime} \mathrm{W}$ at $314 \mathrm{~m}$ above sea level. Seventeen ovitraps were distributed in several trees at heights ranging from 1.7-4.3 $\mathrm{m}$. The plant cover in the study area, which was originally typical of Atlantic Forest, is currently undergoing regeneration implemented by AHES technicians. The area surrounding the forest is subject to intense cattle rearing.

The paddles were collected 15 days after the traps were placed in the field. The positive paddles were kept cool and moist during transportation and were separated in the lab- 
oratory. The collected eggs were counted and immersed in transparent pans filled with Mili- ${ }^{\circledR}$ water. Because it was not possible to count the eggs of each species found in each ovitrap, the proportion of hatches per species was analysed in relation to the total number of hatched eggs. Immediately after immersion, the eggs were placed in an experimentally controlled environment in a chamber with a 10:14 (L-D) photoperiod at a temperature of $28^{\circ} \mathrm{C} \pm 1{ }^{\circ} \mathrm{C}$ (Alencar et al. 2008). Larvae that hatched were reared using standard entomological techniques to obtain adults for taxonomic determination. After three days, the paddles were removed from the water. Dipping was repeated at intervals of two days until no further hatchings were observed. The proportion of hatchings per immersion varied between collections and was recorded for up to 30 immersions for Haemagogus. Eggs that did not hatch were not considered in the subsequent analysis and no attempt was made to assess their viability.

The taxonomic determination of the hatched specimens was based on direct observation of morphological characters through a stereoscopic microscope and a transmitted light microscope using dichotomy keys pro-
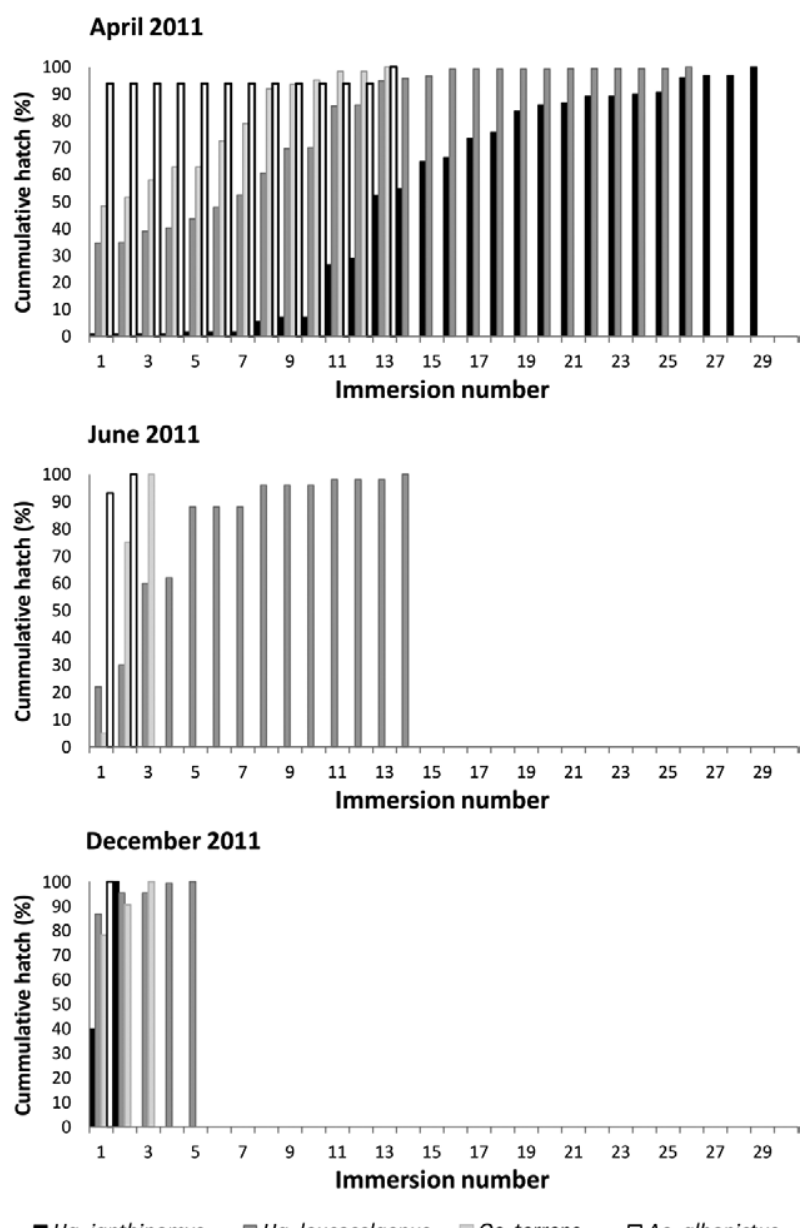

-Hg.janthinomys $\square \mathrm{Hg}$.leucocelaenus $\square$ Oc.terrens $\square$ Ae.albopictus

Fig. 1: egg-hatching rates over three months following consecutive immersions. posed by Arnell (1973) and Forattini (2002). The abbreviations employed for mosquito genera and subgenera are those proposed by Reinert (2001).

Chi-square tests were performed to evaluate whether the median number of immersions that triggered egg hatching (the number of immersions required for $50 \%$ of the eggs) to hatch differed significantly between genera or between month.

The percentage of egg-hatching in all sampling periods combined (April $61.89 \%$, June $32.57 \%$, October $6.25 \%$ and December $11.62 \%$ ) was moderate, with 1,339 out of 3,650 immersed eggs (36.7\%) hatching. The effects of immersion were variable. The eggs of $\mathrm{Hg}$. leucocelaenus displayed the highest percentage of hatching upon first immersion in all of the analysed samples, except the June sample, for which the highest percentage was recorded upon the third immersion. In contrast, $H g$. janthinomys showed the highest percentage of hatching upon the 13th immersion in April and upon the second immersion in December. We observed a cumulative effect of the immersions for $\mathrm{Hg}$. leucocelaenus up to the 13th immersion in April, the eighth immersion in June and the second immersion in December. We also found a cumulative effect of immersion for $\mathrm{Hg}$. janthinomys, up to the 26th immersion in April and the second immersion in December, after which the effect of subsequent immersions was negligible. Most of the hatching of $A e$. albopictus and Oc. terrens eggs occurred following the first-third immersions, though cumulative effects were detected up to 13th immersion for Oc. terrens in April (Fig. 1). Very few eggs (16) were collected for any of the species in October and only one egg hatched ( Hg. leucocelaenus on the 1st immersion).

Significant differences were detected in the median number of immersions that triggered egg hatching in the four species in April (chi-square $=8.4 ; \mathrm{p}<0.05$ ), but not in June $(\mathrm{p}=0.76)$ or December $(\mathrm{p}=0.94)$. Hatching was similar in all months for Ae. albopictus and Oc. terrens ( $\mathrm{p}>0.38$ ), but differed for $\mathrm{Hg}$. janthinomys (chi-square $=4.7 ; \mathrm{p}<0.05$ ) and Hg. leucocelaenus (chi-square $=8.0$; $\mathrm{p}<0.05$ ). The highest percentages of hatching were observed in Haemagogus species in April (Fig. 2).

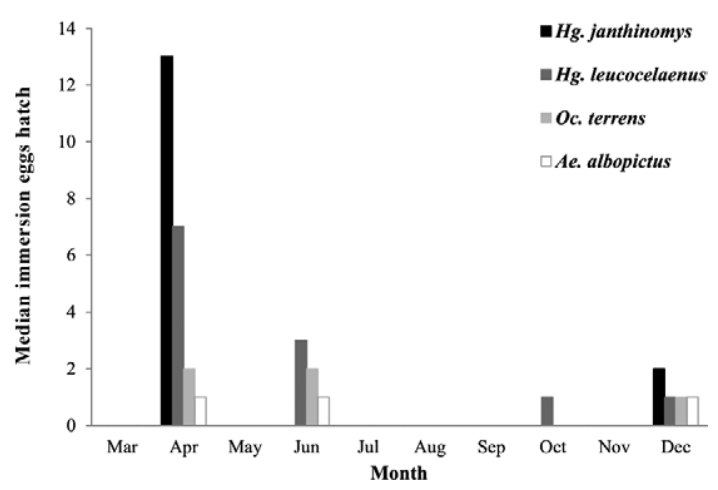

Fig. 2: median number of immersions that trigger egg hatching for Haemagogus janthinomys, Haemagogus leucocelaenus, Aedes albopictus and Ochlerotatus terrens. 
Instalment hatching is known to occur in the Aedini tribe. However, each species analysed in the current study differed in its hatching response. Most $A e$. albopictus eggs hatched upon the first immersion, while the instalment response of $\mathrm{Hg}$. janthinomys and $\mathrm{Hg}$. leucocelaenus varied and was more pronounced in April.

The drought resistance of Haemagogus eggs and the effects of multiple immersions on them are still not well known, despite the relevance of some species as arbovirus vectors. Alencar et al. (2008) noted that Hg. janthinomys eggs hatch in instalments following a sequence of flooding events and that the eggs are still active after several immersions in water. This behaviour allows eggs from one batch to hatch after a rainfall event that is sufficiently strong to submerge them. Eggs of this species were collected in April and December in the present study and showed contrasting hatching patterns. In April, Hg. janthinomys eggs hatched mainly following alternate immersions between the 11th and 26th immersions and only $7 \%$ of the eggs hatched during the first 10 immersions. However, in December, all of the Hg. janthinomys eggs hatched within the first two immersions. A slightly different pattern was observed by Alencar et al. (2008) for eggs collected at a more southerly location. They described a cumulative effect of multiple immersions for $\mathrm{Hg}$. janthinomys between the eighth-10th immersions. However, this pattern was not observed in an experiment conducted by Galindo et al. (1955), who found that most hatching occurred after the third and fourth immersions.

Hg. leucocelaenus and Oc. terrens were similar to $H g$. janthinomys in showing a longer period of instalment hatching in April than in December. However, hatching in both species was highest during the first two immersions and decreased following subsequent immersion events. Hatching of Oc. terrens occurred up to the 13th immersion in April. Galindo et al. (1955) also observed that most hatching occurred in field-collected Hg. leucocelaenus and Oc. terrens eggs from Panama after the first flooding event and continued up to a ninth cycle in Oc. terrens.

Previous reports have indicated that the eggs of $A e$. albopictus may require several flooding events before they hatch (Vitek \& Livdahl 2006). However, the majority of eggs examined in the present study hatched within the first two immersions. These differences may be due to diverse factors, including likely strain variations. Large genetic differences have been found among Brazilian populations and between Brazilian and other American populations (Lourenço-de-Oliveira et al. 2003). Additional differences observed in strains from other parts of the world include photoperiodic diapause during the egg stage in temperate populations and an absence of photoperiodic diapause in some tropical populations (Vinogradova 2007).

Because all eggs were kept in the laboratory under the same conditions and the applied flooding procedure was the same, the differences in instalment hatching observed in Haemagogus must have been due to the environmental conditions to which the females were exposed before laying eggs or the conditions to which the eggs were exposed in the field before they were brought to the laboratory. Campos and Sy (2006) observed that the percentage of hatching in viable same-age Ochlerotatus albifasciatus eggs after flooding was significantly lower for eggs maintained in the field on the ground (in dead leaves at a temperature ranging from $10-15^{\circ} \mathrm{C}$ ) compared to eggs stored in the laboratory at $22^{\circ} \mathrm{C}$. Moreover, exposure to a short cold period (7-21 days) was sufficient to induce some eggs to enter diapause (Campos et al. 2007).

A longer instalment period immediately before and/or during the drought season may be a bet-hedging strategy to ensure that some eggs remain viable if containers do not last for a sufficiently long time to allow larvae to complete their development (Andreadis 1990, Katchikian et al. 2010). In contrast, the chance that a container will dry out diminishes during the rainy season and eggs hatching synchronically may therefore be more likely to reach adulthood. The eggs of all species (except Ae. albopictus) collected in April, just prior to the drought season, when rainfall was decreasing, consistently hatched (or continued to hatch) in the laboratory after a greater number of immersions compared to those collected in December, when the highest rainfall levels are recorded in the field. This decrease in the number of immersions required for eggs to hatch was more evident in $\mathrm{Hg}$. janthinomys, whose eggs hatched after 15 immersions on average in April and fewer than two immersions in December.

The maternal influence on the physiological state of eggs has been shown to vary between species (Anderson 1968, Vinogradova 2007), but the existence of maternal influence is unknown in $\mathrm{Hg}$. janthinomys, $\mathrm{Hg}$. leucocelaenus and Oc. terrens. Further studies under controlled laboratory conditions are required to confirm these hypotheses.

\section{ACKNOWLEDGEMENTS}

To the research technician, Carlos Salvador (Engevix), for their collaboration in field activities.

\section{REFERENCES}

Alencar J, Almeida HM, Marcondes CB, Guimarães AE 2008. Effect of multiple immersions on eggs and development of immature forms of Haemagogus janthinomys from South-Eastern Brazil (Diptera: Culicidae). Entomol News 119: 239-244.

Alencar JA, Gil-Santana HR, Lopes CM, Santos JS, Guimarães AE 2004. Utilização de armadilha "ovitrampa" para monitoramento de Haemagogus janthinomys (Diptera: Culicidae) em área de Mata Atlântica. Entomol Vector 11: 369-372.

Anderson J 1968. Influence of photoperiod and temperature on the induction of diapause in Aedes atropalpus (Diptera: Culicidae). Entomol Exp Appl 11: 321-330.

Andreadis TG 1990. Observations on instalment egg hatching in the brown saltmarsh mosquito, Aedes cantator. J Am Mosq Control Assoc 6: 727-729.

Arnell JJ 1973. Mosquito studies (Diptera, Culicidae). XXXII. A revision of the genus Haemagogus. Contributions of the American Entomological Institute 10: 1-174.

Campos RE, Sy VE 2006. Variation in the hatching response of Ochlerotatus albifasciatus egg batches (Diptera: Culicidae) in temperate Argentina. Mem Inst Oswaldo Cruz 101: 47-53. 
Campos RE, Sy VE, Castro L 2007. Effects of continuous drought and immersion on hatchability of Ochlerotatus albifasciatus (Diptera: Culicidae) eggs stored at low temperature. Rev Soc Entomol Argent 66: 131-137.

Consoli RAGB, Lourenço-de-Oliveira R 1994. Principais mosquitos de importância sanitária no Brasil, Editora Fiocruz, Rio de Janeiro, $228 \mathrm{pp}$.

Forattini OP 2002. Culicidologia médica, EDUSP, São Paulo, 860 pp.

Galindo P, Carpenter SJ, Trapido H 1955. A contribution of ecology and biology of tree-hole breeding mosquitoes of Panama. Ann Entomol Soc Am 48: 158-164.

Gillett JD 1955. Variation in the hatching-response of Aedes eggs (Diptera: Culicidae). Bull Entomol Res 46: 241-254.

Khatchikian CE, Dennehy JJ, Vitek CJ, Livdahl TP 2010. Environmental effects on bet hedging in Aedes mosquito egg hatch. Evol Ecol 24: 1159-1169.

Lourenço-de-Oliveira R, Vazeille M, de Filippis AMB, Failloux AB 2003. Large genetic differentiation and low variation in vector competence for dengue and yellow fever viruses of Aedes al- bopictus from Brazil, the United States and the Cayman Islands. Am J Trop Med Hyg 69: 105-114.

Marcondes CB, Alencar J 2010. Revisão de mosquitos Haemagogus Williston (Diptera: Culicidae) do Brasil. Rev Biomed 21: 221-238.

Mullen GR, Durden LA 2009. Medical and veterinary entomology, 2nd ed., Academic Press, Amsterdam, 637 pp.

Reinert JF 2001. Revised list of abbreviations for genera and subgenera of Culicidae (Diptera) and notes on generic and subgeneric changes. J Am Mosq Control Assoc 17: 51-55.

Reinert JF, Harbach RE, Kitching IJ 2008. Phylogeny and classification of Ochlerotatus and allied taxa (Diptera: Culicidae: Aedini) based on morphological data from all life stages. Zool J Linn Soc 153: 29-114.

Vinogradova EB 2007. Diapause in aquatic insects, with emphasis on mosquitoes, In VR Alekseev, B de Stasio, JJ Gilbert, Diapause in aquatic invertebrates, theory and human use, Series: Monographiae Biologicae 84, Springer-Verlag, New York, p. 83-113.

Vitek CJ, Livdahl TP 2006. Field and laboratory comparison of hatch rates in Aedes albopictus (Skuse). $J$ Am Mosq Control Assoc 22: 609-614. 